\title{
Dilemma of seizure prophylaxis in sub-arachnoid haemorrhage
}

\section{Binny Mahendru*}

Department of Pharmacology, Dr Rajendra Prasad Government Medical College, Kangra at Tanda, Himachal Pradesh, India

Received: 16 January 2021

Accepted: 11 February 2021

*Correspondence:

Dr. Binny Mahendru,

Email: drbinnymahendru@gmail.com

Copyright: (C) the author(s), publisher and licensee Medip Academy. This is an open-access article distributed under the terms of the Creative Commons Attribution Non-Commercial License, which permits unrestricted non-commercial use, distribution, and reproduction in any medium, provided the original work is properly cited.

\begin{abstract}
There is around $10 \%$ risk of developing seizures in post subarachnoid hemorrhage (SAH) period. This is considered to be linked to decreased oxygenation of brain due to increase in intra-cranial pressure obviating use of anti-epileptic drugs (AED) as a prophylactic measure. This review was done to study the effect and changes of blood brain barrier permeability in subarachnoid hemorrhage with regard to the present knowledge available and how it could be utilized to open arenas for future research for the rationalization of therapy for such patients. There is no consensus till date on the etiopathogenesis due to which no established guidelines are present for the management of such patients. It is safer to approach the patient on a case by case basis and assess whether to give prophylaxis or not based on the risk of development of seizures and adverse event profile of drugs. Also, there is a need to conduct prospective studies in this arena so as to get some meaningful interpretations which could be of some use to the future therapeutic guidelines.
\end{abstract}

Keywords: Subarachnoid hemorrhage, Seizure, Blood brain barrier, Anti-epileptic drug

\section{INTRODUCTION}

After an episode of subarachnoid hemorrhage (SAH), there is around $10 \%$ risk of developing seizures. ${ }^{1,2}$ The etiopathogenesis may be linked to decreased oxygenation of brain due to increase in intra-cranial pressure. ${ }^{3}$ So there is a routine practice to use anti-epileptic drugs (AED) as a prophylactic measure to avoid seizure occurrence. Some researchers have linked increase in blood brain barrier (BBB) permeability also to the development of ischaemia. ${ }^{4,5}$ There is no consensus till date on the etiopathogenesis due to which no established guidelines are present for the management of such patients. In this review, we would be reviewing the effect and changes of blood brain barrier permeability in subarachnoid hemorrhage with regard to the present knowledge available and how it could be utilized to open arenas for future research for the rationalization of therapy for such patients.

\section{SUBARACHNOID HEMORRHAGE}

Experiments in animals have confirmed the genesis of hyperexcitability and epilepsy with the disruption of blood brain barrier. ${ }^{6-9}$ These injuries can lead to disturbance in ubiquitin-proteasome pathway. Alterations in such molecular transduction pathways can lead to degradation of the extracellular matrix and hence disrupted blood brain barrier.10 These are henceforth linked to delayed cerebral ischemia and poor prognosis. ${ }^{11}$ This has also been supported by clinical trials. ${ }^{12}$

Li et al in 2015 have tried to explore the molecular mechanisms underlying changes in blood brain barrier permeability and acute injury to the brain after an episode of SAH. ${ }^{13} \mathrm{He}$ concluded the opening of tight junctions post SAH lead to increased BBB permeability which showed peaks at 3 hours and 72 hours after the hemorrhage. There was down regulation of the Occludin and Zo-1 expression and hence it was established that $\mathrm{Akt} / \mathrm{FOXO}$ signaling 
pathway may be linked to regulation of tight junction opening and also the BBB permeability in the initial phase of SAH.

Germano et al in 2000 have also established that there is a correlation between increase in BBB permeability with delayed cerebral ischemia and worse prognosis. This study also provided a quantitative description of the temporal progression and recovery of BBB dysfunction after SAH. ${ }^{14}$

It has been seen that the incidence of seizures in post-SAH patients is almost around $26 \%$. Based on the onset, these have been classified as: immediate ( $<1$ day), early onset $(1$ day to one week) and late onset ( $>1$ week). Late onset has been seen in only 3-7\% cases. So there is greater need for seizure prophylaxis in the early period. The advocates of beginning seizure prophylactic therapy justify it by saying seizure occurrences lead to greater risk of neurologic injuries, longer duration of hospital stays, increased treatment cost, diminished recovery etc. So there is a practice to start anti-epileptic drugs in these patients of SAH. This accounts to almost $65 \%$ patients who are put on these AEDs. In a survey in 2015 in the United States, 52\% physicians of big academic centers recommend to give AED as a prophylaxis for seizures in the post SAH period. ${ }^{15}$

Among the various AEDs, phenytoin has been used since long as the primary agent. Levetiracetam is the recent drug becoming favourite of all. Other AEDs being tried for this indication include carbamazepine, valproic acid, phenobarbitone. But none of these is being tried as the primary agent to prevent seizures in the post SAH period. Still there is no established guideline for this issue as there are many adverse concerns with the use of these AEDs. Phenytoin causes many adverse drug reactions, requires TDM (therapeutic drug monitoring), and disturbed cognition and drug interactions due to CYP450 enzymes. Further, TDM is also deranged due to changes in albumin levels.

On the other hand, problems with levetiracetam are also not few to begin with. It has been linked with increase in behavioral abnormalities, shorter duration may not be sufficient plus it has not been studied as a monotherapy in this subset of patients.

Considering the adverse event profiles of all these therapies, there is a big lobby of physicians who do not routinely use AEDs for seizure prophylaxis in the SAH. This segment also accounts to as high as almost $40 \%$. Their main sword is the adverse effect profile of AEDs. They also advocate that use of AEDs is associated with higher incidences of in-hospital complications plus drug related events and interactions like fever, rash, CYP interactions, etc. Moreover, the clinical outcome based on GCS and functional status on discharge is also considered to have a worse facet. So they give rationale against the prophylaxis of seizures in post $\mathrm{SAH}$ patients.
To follow the middle path, it is safer to approach the patient on a case by case basis and assess whether to give prophylaxis or not based on the risk of development of seizures and adverse event profile of drugs. Though theoretically quite possible, a balance of all these considerations may not be easy to achieve clinically.

\section{CONCLUSION}

What we can analyze simply is that this issue of seizure prophylaxis in post SAH patients has no established therapeutic guidelines till date. The reason could be lack of literature on this topic to formulate therapeutic guidelines for the treatment. Almost all the studies have been retrospective which do not suffice. We don't even have consensus on what should be the duration of this prophylaxis, leave aside what agent to use. Hence there is a dire need to conduct prospective studies in this arena so as to get some meaningful interpretations which could be of some use to the future therapeutic guidelines.

\section{ACKNOWLEDGEMENTS}

The author is thankful to Dr Smita Pattanaik for guiding in manuscript preparation.

\section{Funding: No funding sources \\ Conflict of interest: None declared \\ Ethical approval: Not required}

\section{REFERENCES}

1. Hasan D, Schonck RS, Avezaat CJ, Tanghe HL, van der Lugt PJ. Epileptic seizures after subarachnoid hemorrhage. Ann Neurol. 1993;33:286-91.

2. Rose FC, Sarner M. Epilepsy after ruptured intracranial aneurysm. Br Med J. 1965;5416:18-21.

3. Rhoney DH, Tipps LB, Murry KR, Basham MC, Michael DB, Coplin WM: Anticonvulsant prophylaxis and timing of seizures after aneurysmal subarachnoid hemorrhage. Neurology. 2000;55:258-65.

4. Germano A, d' Avella D, Imperatore C, Caruso G, Tomasello F. Time-course of blood brain barrier permeability changes after experimental subarachnoid hemorrhage. Acta Neurochir (Wien). 2000;142:57580.

5. Jin X, Liu J, Yang Y, Liu KJ, Yang Y, Liu W. Spatiotemporal evolution of blood brain barrier damage and tissue infarction within the first $3 \mathrm{~h}$ after ischaemia onset. Neurobiol Dis. 2012;48:309-16.

6. Seiffert E, Dreier JP, Ivens S, et al. Lasting bloodbrain barrier disruption induces epileptic focus in the rat somatosensory cortex. J Neurosci. 2004;24:782936.

7. Ivens S, Kaufer D, Flores LP. TGF-beta receptor mediated albumin uptake into astrocytes is involved in neocortical epileptogenesis. Brain. 2007;130:535-47.

8. Heinemann U, Kaufer D, Friedman A. Blood-brain barrier dysfunction, TGFb signalling and astrocyte dysfunction in epilepsy. Glia. 2012;60:1251-7. 
9. Lapilover EG, Lippmann K, Salar S. Peri-infarct blood-brain barrier dysfunction facilitates induction of spreading depolarization associated with epileptiform discharges. Neurobiol Dis. 2012;48:495-506.

10. Jin R, Yang G, Li G. Molecular insights and therapeutic targets for blood-brain barrier disruption in ischemic stroke: critical role of matrix metalloproteinases and tissue-type plasminogen activator. Neurobiol Dis. 2010;38:376-85.

11. Yan J, Li L, Khatibi NH. Blood-brain barrier disruption following subarachnoid hemorrhage may be facilitated through PUMA induction of endothelial cell apoptosis from the endoplasmic reticulum. ExpNeurol. 2011;230:240-7.

12. Tomkins O, Shelef I, Kaizerman I. Blood-brain barrier disruption in post-traumatic epilepsy. J NeurolNeurosurg Psychiatry. 2007;79:774-7.

13. Li Z, Liang G, Ma T, Li J, Wang P, Liu L et al. Bloodbrain barrier permeability change and regulation mechanism after subarachnoid hemorrhage. Metab. Brain Dis. 2015;30(2):597-603.

14. Germanò A, d'Avella D, Imperatore C, Caruso G, Tomasello F. Time-course of blood-brain barrier permeability changes after experimental subarachnoid haemorrhage. Acta Neurochir (Wien). 2000;142(5):575-80.

15. Dewan MC, Mocco J. Current practice regarding seizure prophylaxis in aneurysmal subarachnoid hemorrhage across academic centers. J Neurointerv Surg. 2015;7(2):146-9.

Cite this article as: Mahendru B. Dilemma of seizure prophylaxis in sub-arachnoid haemorrhage. Int J Basic Clin Pharmacol 2021;10:306-8. 